admission have to be insisted on. The ward has never been more than half full. With its small number of patients, the actual nursing staff of approximately 18 has seemed the correct number. With the full complement of patients, a nurse/patient ratio of $1.5 / 1$ would not be adequate.

Two equal groups of patients are emerging. One group is more treatable and more dischargeable irrespective of the reason for admission, the other is much more long-stay and untreatable in that the patients periodically cause further problems. Many of this latter group will need to be in this ward for longer than two years. Where are these patients to go? Two forms of management are also emerging, one group of patients being returned to their catchment area team, the other being retained by the staff of the ward.

Finally, difficulties in management and in relationships with colleagues which can be expected by Regional Secure Units are already being seen in this ward. It would seem unwise to contemplate opening a Regional Secure Unit without attempting to solve these locally in a smaller unit.

\title{
2. THE LYNDHURST UNIT AT KNOWLE HOSPITAL, FAREHAM, HANTS
}

By Dr M. Faul.K

Consultant Forensic Psychiatrist, Wessex Region

By the 1970s three groups of psychiatric patients were receiving a particularly poor deal from the National Health Service: (a) The psychopathic patients who had never received the special facilities recommended by the DHSS; (b) A new group of patients, i.e. the difficult or dangerous psychotic patients who are now being refused admission to local hospitals, but whose behaviour is not such as to require the care of a Special Hospital; (c) The difficult or dangerous subnormal patients who could not be managed in new style or overcrowded, understaffed subnormality hospitals.

The planning and consultation for our unit lasted from 1971 to 1977. I had the considerable support of the Deputy Regional Medical Officer right from the start. The major breakthrough occurred once the consultant psychiatrists at Knowle Hospital agreed that an in-patient unit for Forensic Psychiatry could be developed there.

Officers and their authorities at Region, Area and District had to be convinced of the need and feasibility. Locally, the nursing managers and shop stewards had to be convinced. Genuine consultation at a very early stage, both formal and informal, demonstration of case histories, visits to prisons and Special Hospitals with shop stewards and others, were all part of the process needed to demonstrate the problem and obtain support and advice on a solution.

Only when all bodies were in support of the Unit did we consult directly with the public through an open meeting, although preliminary press releases had been made right through all the planning stages.

I found the consultations with other disciplines much more than a paper exercise. I found the advice of nursing colleagues and shop stewards extremely useful and beneficial to the Unit. The question of physical security was very taxing. I was unsure if it was necessary or desirable. The Unions insisted on there being a minimum of physical security only, i.e. just enough so that it could be used if needed. Their fear was that a permanently physically secure unit might deteriorate, especially at times of low staffing, into an old-fashioned locked back ward. They also felt, and this feeling has been echoed by local town councillors, that a fully secure unit would encourage the DHSS or others to urge the Unit to care for patients who properly should be in a Special Hospital, i.e. they felt that there would, in the end, be less risk in running a unit with less rather than more security.

This point of view was compatible with my own view of how such a unit should run to deal with the clinical problems which I was likely to meet. My experience and reading had led me to believe that patients' bad behaviour owes much more to environmental stresses from the institution than is generally recognized. It seemed to me that if patients could be helped to feel well and free of anxiety, whatever the cause, then their chances of acting dangerously would be minimized. I had come to the view that this could be achieved (a) by proper detailed clinical medical attention coupled with (b) nursing care based on the acceptance and understanding of individuals, and (c) the creation of a milieu on the Unit in which the patient could receive attention and sympathy easily and rapidly, with a minimum of institutional rules.

It seemed to me that a punitive or authoritarian regime was inappropriate in the open setting we would have. In such a setting the settling down of a patient, who might be sometimes angry, hostile or very tense and frightened, was best done, as far as possible, by reducing tension, by giving appropriate 
attention rather than by confrontation. Only when a situation was immediately and truly dangerous should it be necessary to control in some physical way.

The final stage before the opening of the Unit was the appointment of nursing staff for a two month Induction Course, consisting of visits, seminars and talks aimed at increasing their understanding of patients' backgrounds, prison system, hospitals, courts, hostels, etc. Great emphasis was placed on understanding personality development, institutions and the interaction of patient and institution, and how the institution is so often provocative. The largest part of the Induction programme was spent in drawing up a document of our daily timetables and practice, trying to put into practical terms the policies and attitudes which I wished to utilize in the care of these difficult patients. It was often only at this point of deciding practice that basic differences in attitudes between staff became apparent, e.g. deciding what to do when patients would not rise in the morning.

Policy

We have tried to restrict admission to those patients who clearly ought to be in hospital but cannot be managed in their own catchment area hospital because their behaviour is considered too difficult or too dangerous. The two main exceptions which we have tried to avoid are the mentally handicapped, as far as possible, and very chronic deteriorated schizophrenics, who have spent, say, twenty years in a hospital and are going through a disturbed phase. We have kept an open mind about the personality disordered and sexual offenders, but have found ourselves admitting quite a number. The criteria for admission do not refer to their legal status or offender status, and we have therefore had patients under many different legal categories as well as informal patients. Some of our patients have come to us as a result of an offence, some have a history of offending in the past, and some have committed acts which are properly offences but for which no legal action has been taken.

The Unit aims to assist the patients by trying to reduce their feelings of tension and frustration by giving them considerably more individual attention than is possible in ordinary wards. We try to allow our interaction with in-patients to be governed foremostly by individual rather than by house rules. I had been very impressed by studies which indicate that the core of a therapeutic regime with such disturbed people lies in the provision of great tolerance, warmth and empathy combined with appropriate firmness. It is very difficult to convey the practical effects of this. As far as possible we try to work with the patient, to discuss with him ways and means, to persuade rather than to dominate, and convince rather than order. The sanctions we impose are largely those of society. Violent or grossly destructive behaviour is reported to the police. Persistent extremely dangerous behaviour may require transfer to a Special Hospital, and we have had to do this in two cases. Minor infringements, e.g. shouting, screaming, petty stealing, are dealt with by discussion.

Our secure room is used only to contain people during a violent outburst until they calm down. It was used twice in the first six months and then for only 15 minutes on each occasion. The ward is locked only if someone is particularly disturbed at that time and likely to leave and do damage. We require patients to let us know where they are going, if on parole: we try to run a dry ward and smoking is banned in bed: otherwise all other conventions are negotiable and are those of society. The effect of having our large staff numbers does, I think, have a controlling effect on its own, i.e. it is as though mother is always around.

\section{Structure}

The Unit is a converted ward on the first floor of the hospital. It is the base for both in-patient and day patient care. There are 14 single bedrooms containing normal equipment, normal windows which are not locked and have no locks on them. The offices on the ward are those for OT, a group room for staff meetings and other purposes, registrar's office and a nursing office. There are two secure rooms, four entrances (all of which can be locked).

The staff for the Unit for $\mathbf{2 4}$ hour cover is $\mathbf{3 0}$ nurses, which includes a nursing officer to look after the ward as well as another part of the hospital, 3 charge nurses, 10 staff nurses, 8 SEN's, 8 NA's. We also have a domestic assistant, social worker, psychologist (parttime), an OT part-time, a registrar, a senior registrar and myself.

Our routine is that a new patient, as a precaution, is kept in night clothes and dressing gown for three days, confined to the usually unlocked ward. This trial period is followed by assessment of need for parole, medication, etc. Our aim is to get people on to full parole as rapidly as possible. We rely on the fact that our patients are not persistently dangerous, minute in, minute out, but have long periods of relative stability with short periods of worrying behaviour. We depend on detecting the start of this behaviour and intervening before it erupts. We are also conscious that undue restriction breeds its own reaction. The patients will spend their day as soon as possible off the ward in the various hospital activity areas alongside the main hospital patients, though escorted if necessary. The evenings are spent around the hospital leisure areas or 
in the company of nurses. Trips, etc, are arranged for weekends as frequently as possible. As the patient improves arrangements are made, where appropriate, for him to go to a hostel, his catchment area hospital, or to lodgings. In appropriate cases patients may attend as day patients or out-patients afterwards. Our nurses have access to a Unit hospital car which is used for home visits, assisting patients to visit, or to find jobs, etc, picking up stranded patients, or other tasks.

I should mention that our social worker and psychologist, apart from conventional work, are also starting special task-orientated groups on the ward, e.g. social skills group; the nurses work alongside certain patients in other groups doing tasks together, which is of great assistance in helping the unsocialized patient. Interdisciplinary consultation and discussion is the backbone of all our work. All decisions from the admission of the patient to treatment are the result of discussion between relevant staff. I would like to think that all members of the staff are able to contribute to all discussions and their opinions will all be respected. Staff meetings where attitudes, opinions and experience can be exchanged are therefore crucial to the running of the Unit.

The Future

It seems to us that in the Unit we have has been able to cope with all kinds of cases referred to us which are clearly not Special Hospital problems, that is to say, we think that if we had physical security it would not alter the patients we look after unless we were a very large unit and were virtually emulating a Special Hospital.

Our plans for expansion at present are therefore merely to replicate our present arrangement. There was some discussion as to whether the new Unit should be on the same site as the present one or at the opposite end of the Region. The advantage of the latter arrangement might be the better overall service to the Region, but it was decided that the Units should be on the same site to share and keep together the experience and expertise. We believe that given, say, 30 beds in total, in conjunction with the intensive care wards in the local hospitals, and the development of houses in the community, under our supervision, in association with day care and out-patient care, we should be able to manage the clinical problems presented to us. Other problems the Region must now look at are (a) the failure to provide anything new for the psychopath, though the Butler Committee put the onus for doing this on the Home Office through the Prison Service and Probation Service, and (b) to improve the services for the subnormal offending patient; for, as the Oxford Survey showed, their numbers are probably as large as those of the mentally ill. At present our Region is trying to make arrangements in our subnormality hospitals to cope with this. 